Running head: Improving psychology students’ attitudes toward schizophrenia

IMPROVING PSYCHOLOGY STUDENTS' ATTITUDES TOWARD PEOPLE WITH SCHIZOPHRENIA:

A QUASI- RANDOMIZED CONTROLLED STUDY

MAGLIANO, L., RINALDI, A., COSTANZA, R., DE LEO, R., SCHIOPPA, G., PETRILLO, M., READ, J. (2016). Improving psychology students' attitudes towards people diagnosed with 'schizophrenia': A quasirandomized controlled trial. American Journal of Orthopsychiatry. doi: 10.1037/ort0000161

${ }^{a}$ Department of Psychology, Second University of Naples, Italy

${ }^{\mathrm{b}}$ Professor John Read, School of Psychology, University of East London, Stratford, London, United Kingdom

Corresponding author: Lorenza Magliano

Corresponding author at: Department of Psychology, Second University of Naples, Italy - Viale Ellittico 31,

81100 Caserta, Italy; phone/fax +39 0823 275358; e-mail: lorenza.magliano@unina2.it

Running head: Improving psychology students' attitudes toward schizophrenia

IMPROVING PSYCHOLOGY STUDENTS' ATTITUDES TOWARD PEOPLE WITH SCHIZOPHRENIA: 
ABSTRACT

Despite scientific evidence that the majority of People With Schizophrenia (PWS) have personal histories of traumatic life events and adversities, their needs for psychological support often remain unmet. Poor availability of non-pharmacological therapies in schizophrenia may be partly due to professionals' attitudes toward people diagnosed with this disorder. As future health professionals, psychology students represent a target population for efforts to increase the probability that PWS will be offered effective psychological therapies. This quasirandomized controlled study investigated the effect of an educational intervention, addressing common prejudices via scientific evidence and pre-recorded audio-testimony from PWS, on the attitudes of psychology students towards PWS. Students in their fifth year of a master's degree in Psychology at the Second University of Naples, Italy were randomly assigned to an experimental group - which attended two three-hour sessions a week apart - or to a control group. Compared to their baseline assessment, at one-month reassessment, the 76 educated students endorsed more psychosocial causes and more of them recommended psychologists in the treatment of schizophrenia. They were also more optimistic about recovery, less convinced that PWS are recognizable and unpredictable and more convinced that treatments, pharmacological and psychological, are useful. No significant changes were found, from baseline to one-month reassessment, in the 112 controls. At one-month reassessment, educated students were more optimistic about recovery and less convinced that PWS are unpredictable than controls. These findings suggest that psychology students' attitudes toward PWS can be improved by training initiatives including education and indirect contact with users. 


\section{IMPROVING FUTURE PSYCHOLOGISTS' ATTITUDES TOWARD PEOPLE WITH SCHIZOPHRENIA: A QUASI-RANDOMIZED CONTROLLED STUDY.}

\section{INTRODUCTION}

Despite consistent scientific evidence that the majority of People diagnosed With Schizophrenia (PWS) have personal histories of traumatic life events and adversities (Read, Magliano, \& Beavan, 2013; Varese et al., 2012), they often are not offered psychological therapies (Hansson et al., 2001; Mojtabai, Fochtmann, Chang, Kotov, Craig \& Bromet, 2009). In particular, studies examining service users' perceptions of needs for care, reveal that PWS want better emotional support - including better access to psychological therapies - and stability in their relationships with health professionals (Mojtabai et al., 2009). There is strong evidence for the efficacy of several psychological therapies for clinical and functional recovery in schizophrenia (Balter, 2014; Liberman, 2008; Mojtabai, Nicholson \& Carpenter, 1998; Morrison, 2013; Pfammater, Junghan \& Brenner, 2006). Among the treatments whose efficacy have been repeatedly proved by rigorous studies are Cognitive-Behavioral Therapy and Family Psycho-education. Cognitive-Behavioral Therapy for psychosis aims at reducing the distress experienced by PWS, by helping them to achieve their own specific goals in relations to problems they have identified themselves (Morrison, 2013; Wykes, Huddy, Cellard, McGurk \& Czobor, 2011). A number of Randomized Controlled Trials proved the efficacy of Cognitive-Behavioral Therapy in reducing symptoms of schizophrenia and in improving functioning compared to routine care and treatment-as-usual (Balter, 2014; Dixon et al., 2010; Morrison, 2013; Morrison et al., 2014). This therapy is generally recommended as an adjunctive treatment to antipsychotic drugs in schizophrenia. However, a recent trial (Morrison et al., 2014) tested the benefit of CognitiveBehavioral Therapy in patients with this disorder who chose not to take antipsychotic drugs. This study found that this therapy significantly reduced psychotic symptoms compared to treatment-as-usual and seemed to be a safe and acceptable alternative to medication for some people with PWS (Howes, 2014). Although the efficacy of Cognitive-Behavioral Therapy in schizophrenia has been confirmed by meta-analyses (Sarin, Wallin, \& Widerlöv, 2011), and the use of this therapy is recommended by several guidelines for this disorder (Dixon et al., 2010; Gaebel, Weinmann, Sartorius, Rutz \& McIntyre, 2005; NICE, 2014), its availability is still poor in most countries. For instance, a study in 19 Italian Mental Health Services (Semisa et al., 2008), found that in $60 \%$ of Mental Health Services no PWS received cognitive-behavioral therapy. Another study of 187 randomly selected PWS in contact with mental health services in North-West England (Haddock, Eisner, Boone, Davies, Coogan \& Barrowclough, 2014), found that only ten received cognitive-behavioral therapy within the twelve-month audit 
period. A systematic review of the literature exploring if the UK recommendations for psychological interventions for schizophrenia were being met (Ince, Haddock \& Tai, 2015) found a rate of implementation varying from 4\% to $100 \%$. A study examining the conformance of usual care for persons with schizophrenia to the Schizophrenia Patient Outcomes Research Team (PORT) Treatment Recommendation in two American States (Lehman \& Steinwachs, 1998) found that the rates at which patients' treatment conformed to these recommendations were modest at best, generally below 50 percent. In particular, only $45.0 \%$ of outpatients were receiving individual or group therapy, including well-specified combinations of support, education and behavioral and cognitive psychotherapy. As far as Family Psycho-education is concerned, the efficacy of this cognitive-behavioral approach in schizophrenia has been demonstrated by more than 50 randomized controlled trials and meta-analyses (Lincoln, Wilhelm \& Nestoriuc, 2007; Pharoah, Mari, Rathbone \& Wong, 2010). Family Psychoeducation aimed at educating PWS and their relatives about the disorders and improving their communication and problem solving skills - has found to be effective in reducing clinical relapse rates and improving functioning in people diagnosed with schizophrenia, and reducing family burden. Family Psychoeducation is also now recommended by many guidelines for PWS but is also rarely available (Gaebel, 2005; NICE, 2014). The Italian study mentioned above (Semisa et al., 2008) found that in $45.5 \%$ of the Mental Health Services less than $10 \%$ of families received this intervention, while in the Lehman's study (1998) the percentage of families receiving such service was 37.2\%. Finally, the systematic review on the implementation of recommendations for psychological interventions in schizophrenia in UK mental health services (Ince et al., 2015) reported an implementation rate of Family Psychoeducation varying from $0 \%$ to $53 \%$.Furthermore, psychological approaches that explicitly target neurocognition such as the Cognitive Remediation therapy (CR) has proved to be effective for ameliorating social cognitive impairments associated with the schizophrenia spectrum (Revell, Neill, Harte \& Drake, 2015; Wykes, Huddy, Cellard, McGurk \& Czobor, 2011). Finally, the Open Dialogue approach (Seikkula, Aaltonen, Alakare, Haarakangas, Keränen \& Lehtinen, 2006), innovative in its psychosocial dimensions, can be considered a promising practice for which some evidence of efficacy has been accumulated (Aaltonen, Seikkula \& Lehtinen, 2011; Seikkula, Alakare \& Aaltonen, 2011).

Limited availability of effective psychological therapies for psychosis in clinical settings is paralleled by the low number of psychologists routinely working with people with severe mental illness (Buck, Romeo, Olbert, \& Penn, 2014; Roe, Yanos, \& Lysaker, 2006). The Italian study by Semisa et al. (2008) revealed that in $63.6 \%$ of the services, less than $10 \%$ of psychologists were skilled in cognitive-behavioral approaches for psychosis. Another study found that training courses in cognitive-behavioral approaches for psychosis were available in only 
$45 \%$ of US psychiatry residency and clinical psychology doctoral programs (Kimhy, Tarrier, Essock, Malaspina, Cabannis \& Beck, 2013), and that $60 \%$ of training directors believed that this psychological therapy was not efficacious in schizophrenia. Variations among countries in the use of evidence-based psychological interventions for schizophrenia have been detected (Ince et al., 2015; Kuller, Goisman, Wainwright \& Rabin, 2010) . This may be related to several factors, including healthcare policy (Ince et al., 2015; Kuller et al., 2010; Mueser, Silverstein \& Farkas, 2013a), influence of the pharmaceutical industry, historical influence of psychoanalysis, and health professionals' cultural attitudes (Buck, Romeo, Olbert, \& Penn, 2014; Deacon, 2013; Servais \& Saunders, 2007). A study on clinical practices and views of the efficacy of Cognitive-Behavioral Therapy in schizophrenia in 214 US and UK clinicians (70.6\% clinical psychologists; Kuller et al., 2010), found that UK participants were more likely to practice Cognitive-Behavioral Therapy, rated this therapy's effectiveness more highly, and were more optimistic about the chances of recovery in schizophrenia.

Poor availability of non-pharmacological therapies for schizophrenia in routine settings may be also due to professionals' attitudes toward people with this disorder (Prytys, Garety, Jolley, Onwumere \& Craig, 2011). Some studies have found that psychologists tend to interact less with PWS than with persons with other mental health problems (Buck et al., 2014), and to view them as having poor insight and motivation for treatments (Reddy, Spaulding, Jansen, Menditto, Pickett, 2010 cited by Mueser et al., 2013a). A study on perceptions of people with a range of mental disorders in a randomly selected sample of 1000 clinical psychologists (response rate: $34 \%$; Servais \& Saunders, 2007) found that psychologists viewed PWS as considerably more ineffective and incomprehensible that individuals with other types of mental disorders, and as the most dissimilar to the psychologists themselves. These perceptions may negatively influence both clinicians' willingness to engage PWS in therapies, and PWS seeking help for fear of encountering negative reactions by health care providers (Serafini et al., 2011; Servais \& Saunders, 2007).

As future health professionals, psychology students represent a target population for efforts to increase the probability that PWS will be offered a range of treatments, including effective non-pharmacological therapies. Therefore, it is valuable to investigate psychology students' attitudes towards PWS and to design training initiatives to improve their willingness to work with PWS. Findings from the few studies exploring psychology students' views of PWS have reported that these students - similarly to medical students (Magliano, Read, Sagliocchi, Patalano, D’Ambrosio \& Oliviero, 2012; Magliano, Read, Sagliocchi, Patalano \& Oliviero, 2013) are not immune to stigma and are not particularly keen to work with PWS in the future. In particular, they have been found to be significantly less comfortable treating a PWS, compared to people with other mental health 
problems (Buck et al., 2014), to believe that "mental patients" - including PWS - are unpredictable, antisocial and dangerous (Magliano, Read, Rinaldi, Costanzo, De Leo, Schioppa, Petrillo, 2015; Read \& Harré, 2001), and to be skeptical regarding the possibility of recovery of PWS (Magliano et al., 2015).

Findings from the few studies that have specifically investigated whether attitudes of psychology students toward PWS can be changed through training initiatives have found that ad-hoc intervention based on education and contact with PWS, or both, are successful, at least in the short time, in reducing the stereotypes of dangerousness and unpredictability (Lincoln, Arens, Berger, \& Rief, 2008; Read \& Law, 1999), desire for social distance and negative emotions toward PWS (Brown, Evans, Espenschade, \& O'Connor, 2010), and stigma toward PWS or bipolar disorders (Mann \& Himelein, 2008).

In 2011, a new educational intervention on schizophrenia for medical and psychology students, developed in line with findings from studies reported above, was introduced at the Second University of Naples, Italy (Magliano et al., 2014). The intervention, administered to 211 medical and psychology students was successful in increasing students' acknowledgment of the psychosocial factors underlying schizophrenia and reducing students' prejudices against PWS, at immediate post-intervention reassessment. In particular, the percentage of students who firmly believed that PWS are unpredictable decreased from $26 \%$ at baseline to $7 \%$ at post-intervention, and the percentage who believed PWS were somewhat or very dangerous fell from $96 \%$ to $77 \%$. Importantly, the percentage of students who firmly believed that PWS could recover increased from $29 \%$ at baseline to $84 \%$ at post-intervention reassessment.

In the current study, the intervention was replicated with a new sample of psychology students, in their fifth year of studies at the Second University of Naples, using a quasi-randomized design, a control group and reassessments one-month after the intervention in the educated students and one month from the baseline assessment in the controls. Seventy six randomly selected students received the educational intervention, while 112 were the controls.

The main hypotheses were that, at the one-month follow up reassessment:

a) educated students would, compared to their baseline assessment: i) identify more psychological factors as causes of schizophrenia; ii) be more convinced of the usefulness of psychological interventions and of the involvement of psychologists in the treatment of schizophrenia; iii) be less convinced that PWS are unpredictable, dangerous, easily recognizable, and affected by an incurable illness

b) controls would, compared to their baseline assessment, not improve in the above listed variables 
c) educated students would improve more than controls in the above listed variables at one-month follow-up reassessment.

\section{METHODS}

\section{Participants}

Participants were psychology students in the second year of a master's degree (corresponding to fifth year of overall psychology training) in 'Psychology Applied to Institutional Contexts at the Second University of Naples. These students undertook compulsory laboratory activities as part of their Psychiatry training during the last semester of their psychology studies. The master's degree in Psychology Applied to Institutional Contexts provides students with psychology skills to work in institutional settings (mainly in the sectors of justice, education, public health services, and companies). It also provides students with basic psychotherapy competences to be further developed in post degree training. In Italy, $87 \%$ of graduate students in general Psychology (threeyear Degree) progress to a Masters degree in psychology (Consorzio Interuniversitario Alma Laurea, 2014), and are expected to become registered/clinical psychologists. In order to be registered as Psychologists, after completing a Master Degree course, psychology students have to attend a mandatory one-year postgraduate practical training in credited institutions, and pass a final exam. In Italy, $80 \%$ of registered Psychologists work as psychologists. Of these, $44 \%$ work in public institutions and 56\% are engaged in clinical activities (Bosio \& Lozza, 2008).

On the basis of their college number (even vs. odd), students were randomly assigned to a group that would have to attend the laboratory activity on prejudices and scientific evidences in schizophrenia (early education group) or to a group who would receive the intervention one month later (control group). Of the 208 students who had to undertake the laboratory activities, 18 students who had been randomly assigned to the early education group asked to be moved to the control group, due to timetable clashes. Therefore, 86 students were included in the education group and 122 were included in the control group. During a laboratory activity held the day before the start of the educational initiative on schizophrenia in the early group, all students were invited to participate in a voluntary evaluation of their views of schizophrenia, which was repeated one month after the intervention in the educated group, and immediately before the start of the educational initiative (one month later) in controls. Of the 208 psychology students who were contacted, all agreed to participate in the assessment study. Twenty (10 students per group) were excluded because of incomplete data (16 did not complete the questionnaire twice, and four did not give back the questionnaire at either assessments Figure 1). Therefore, the analyzed sample 
consisted of 188 students $\left(169,89.9 \%\right.$ female; $M_{\text {age }}=26.3$ years $\pm 4.3 S D$, age range: $23-56$ years; single 174/187, 93.0\%). Of these, 76 students ( $40.4 \%$; 66 female, $86.8 \%, M_{\text {age: }}: 26.9$ years $\pm 5.8 S D$, age range: $23-56$ years; single $69 / 76,90.8 \%)$, were in the educational initiative group and $112\left(59.6 \% ; 103\right.$ female, $92.0 \%, M_{\text {age }}=25.8$ years \pm 2.7 SD; age range 23-45 years; single 105/111, 94.6\%) in the control group (Figure 1). There were no significant differences in socio-demographic variables between the two student groups.

\section{Materials and Procedure}

At the beginning of the Psychiatry course, students were randomly assigned to a group that received the intervention (education group) or to a control group, on the basis of their college number (even vs. odd). Because it was necessary that all students received the same laboratory activities, controls attended the educational intervention after the one-month reassessment.

Since the voluntary evaluation of students' views was associated with a registered laboratory activity (each student had to sign his/her attendance at the laboratory activity), written consent was not asked in order to avoid discrimination against students who refused to participate. Conversely, information on the voluntary evaluation was provided to students by the teacher orally, and also reported on the front page of the questionnaire. Students were invited to leave blank the questionnaire (contained from the second page of the tool) or not to give it back, if they did not want to participate in the assessment. The questionnaire was distributed to eligible participants and collected after 30 minutes by students who were not members of the research working group, in the absence of the teacher.

Students were asked to read a clinical description of schizophrenia according to the ICD-10 criteria for schizophrenia (reported on the front page of the questionnaire) and to complete the Opinions on mental illness Questionnaire (OQ) (Magliano, Fiorillo, De Rosa, Malangone, \& Maj, 2004). Baseline vs one-month questionnaires were matched by using an anonymous numeric code.

The educational intervention included two three-hour sessions with an interval of a week between them (Magliano et al., 2014). The first session addressed stigma and its impact on persons with mental illness, while the second session provided scientific evidences contrasting stereotypes and prejudices towards stigmatized groups. The first session covered the following topics: a) definitions of stereotypes, prejudices and discrimination;

b) theoretical basis, experimental studies and personal stories on stigma and its effects; d) stigma and the media; e) stigma and mental health problems; f) stigma and schizophrenia; g) stigma against persons with mental disorders in health contexts. The second session focused on: a-c) scientific evidence on social dangerousness in 
"at risk" minority social groups, in persons with mental disorders, and in persons with schizophrenia; d) scientific and consumer models of recovery in schizophrenia. As regards scientific models of recovery, the intervention mainly referred to the Remission in Schizophrenia Working Group definition of "recovery as the ability to function in the community, socially and vocationally, as well as being relatively free of psychopathology" (Andreasen, Carpenter, Kane, Lasser, Marder \& Weinberger, 2005; Bellack, 2006). Furthermore, Liberman's standardized operational criteria (2002) of recovery as "a two-year period in which the person is functioning within normal limits in the domains of symptomatology, participating in work and school, living independently, and maintaining social relationships" were also presented. As far as consumer models of recovery, the educational program referred to the Substance Abuse and Mental Health Service Administration definition of recovery (2005), as "a journey of healing and transformation for a person with a mental disability to be able to live a meaningful life in the communities of his or her choice while striving to achieve full human potential or personhood"; e) scientific evidence on recovery in PWS; and f) recovery-oriented and empowerment-based mental health services. In both sessions scientific reports, media articles, cartoons, audio-testimonies, and videos from anti-stigma campaigns were used. In particular, in the section addressing recovery-oriented and empowerment-based mental health services (section $f$ of the second three-hour session) video-testimonies of three persons with a diagnosis of schizophrenia (two males and one female) talking about their experiences and the factors contributing to their recovery process were shown (i.e., pharmacological and non-pharmacological treatments they had received, psychological support provided them by professionals, possibility of sharing the own experiences with other PWS, family and social network support, obtaining a job). The presentations were followed by open discussion with participants, who were prompted to ask questions on the presented materials.

The educational intervention was developed by a working group of medical and psychology students and a teacher, on the basis of stigma literature findings (see materials reported in Appendix 1). Moreover, four women who had recovered from, or who had faced stigma due to, mental health problems, provided audio-taped testimonies of their personal experiences. The audio-taped testimonies, three of which were also available online (see Appendix 1), provided information on the experience of hearing voices and having persecutory delusions, on the impact of biological and psychological treatments and of family and social support on recovery process, on the impact of media on self-stigma, and on stigma in medical contexts.

Some topics were directly presented by students from the working group (sections on stigma in health contexts and on the recovery process) who had received training before their presentation within the educational sessions. The training of the working group consisted of: a) preliminary analysis of stigma literature; b) 
preparation of slides on stigma topics; c) roleplayed sections (within the working group) on the examined stigma topics; d) technical feedback by the members of the working group and the teacher on slide contents and presentation skills (i.e., clearness of exposition, tone of voice, ability to keep the attention and to prompt discussion by means of active listening); e) development of final slides to be presented by the students in the educational sessions.

The study was authorized by the Head of the Faculty of Psychology in agreement with the local Research Ethical Board, and was carried out in March-April 2012 and in March-April 2013. Authors complied with APA ethical standards in the treatment of their sample.

\section{Measures}

The Opinions on mental illness Questionnaire (OQ) is a self-report tool exploring beliefs about: a) the causes of schizophrenia; b) the effectiveness of available treatments and patients' right to be informed about treatments; c) the psychosocial consequences of schizophrenia (i.e., problems that PWS may experience in family and affective relationships, and in social and occupational roles; social distance from and perception of recognizability, dangerousness and unpredictability of persons with the disorder). Four items ask about which professionals should be involved in treatment. Beliefs about causes and appropriate professionals are assessed by yes/no items, while beliefs about b-c variables are rated on a 3-point scales, from $1=$ "not true" to $3=$ "completely true". OQ psychometric properties have been previously tested (Magliano et al., 2004) with Cohen's kappa ranging from .50 and 1 for $74 \%$ of the items; Cronbach alpha ranging between .42 and .72 . Cronbach's alpha for the subscales measured in the study sample ranged from .39 to .79 . For the purposes of this study, only QO exploring: beliefs about the causes of schizophrenia, and about the possibility of recovery, the usefulness of drug and psychological therapies, the involvement of psychologists in treatment, and the recognizability, unpredictability, and dangerousness of PWS were analyzed.

\section{Data analysis}

At baseline, education and control groups were compared with respect to sex, age and marital status by $\chi 2$ and $t$-test, respectively. In the education group, baseline vs. one-month reassessment paired comparisons of students' views about: a) the causes of schizophrenia, and the involvement of psychologists in its treatment were performed using the McNemar test; and comparisons of b-c) recovery, usefulness of drug and of psychological treatments; and recognizability, unpredictability, and dangerousness of PWS were performed using Wilcoxon 
signed-rank test for paired data. The same paired comparisons were performed in the control group. Education and control groups were compared at one-month reassessment with respect to a) variables by using Chi-square $(\chi 2)$, and b-c) variables by using Mann-Whitney $U$ test. Only results at the $p<.05$ with Bonferroni correction are reported (one correction for all analyses, $0.05 / 54=0.0009$ ), to reduce the probability of type I errors (false positives).

\section{RESULTS}

At baseline, heredity $(156 / 188,83.0 \%)$ and psychological traumas $(111 / 188,59.0 \%)$ were the most frequently cited causes of schizophrenia in both groups combined (Table 1). Ninety-four percent (176/188) of students recommended the psychiatrist, while $78.7 \%$ (148/188) of students recommended the psychologist. The majority of respondents firmly believed that psychological interventions are useful in schizophrenia $(111 / 185$, $60.0 \%$ ), while $36.2 \%(67 / 185)$ were convinced of the usefulness of drugs (Table 2).

At baseline, 23\% (36/157, missing: 31) of students believed that it was 'completely true' that PWS could be well again, while $36.5 \%(65 / 178)$ thought it was 'not true' that PWS are easy recognizable. Finally, nearly all the students believed that it was "partially true" or "completely true" that PWS were unpredictable (168/178, 94.4\%, missing: 10 ) and dangerous (165/173, $95.4 \%$, missing 15 ; Table 3). At baseline, no statistically significant differences in views about persons with this disorder were detected between the two student groups.

Compared to their baseline assessment, at one-month reassessment the 76 educated students more frequently mentioned stress $(43.4 \%$ vs. $72.4 \%$, McNemar test: $14.7, p<.05)$ and love disillusionment $(6.6 \%$ vs. $30.3 \%$, McNemar test, $p<.05$ binomial distribution) among the causes of schizophrenia. One-month after the intervention, a higher percentage of students believed that drugs interventions were useful for schizophrenia (33.0\% vs. $53.9 \%$; number of paired valid answers - 75 : percentage of "completely true" : $25 / 75$ (33.0\% vs. 41/75 (54.7\%), Wilcoxon test:-3.9, $p<.05)$. Similarly, a higher percentage thought that psychological therapies were useful (59.2\% vs. $85.3 \%$; number of paired valid answers - 75: percentage of "completely true" : 44/75 (58.7\%) vs. $64 / 75$ (85.3\%), Wilcoxon test:-4.1, $\mathrm{p}<.05)$, and recommended psychologists for treatment $(77.6 \%$ vs. $97.4 \%$, number of paired valid answers - 76; McNemar test: $p<.05$, binomial distribution). The percentage of students who firmly believed that PWS were unpredictable fell from $35.7 \%$ at baseline to $8.7 \%$ at one-month reassessment (number of paired valid answers - 66: percentage of "totally true" : 25/66 (37.8\%) vs. 6/66 (9.0\%), Wilcoxon test: $-5.1, p<.05)$. The percentage of students who believed that PWS are not easily recognizable increased from $38.4 \%$ at baseline to $63.5 \%$ at post-intervention (number of paired valid answers - 71: percentage of "not true": $27 / 71$ 
(38.0\%) vs. $45 / 71$ (63.4\%), Wilcoxon test:-3.5, $p<.05)$. Moreover, the percentage of students who firmly believed that PWS could recover increased from $23.8 \%$ at baseline assessment to $64.9 \%$ at one-month reassessment (number of paired valid answers - 63: percentage of "completely true" computed on paired answers: 15/63 (23.8\%) vs. $40 / 63$ (63.4\%), Wilcoxon test: $-4.2, p<.05)$. In the control group, no statistically significant differences were found when initial assessment was compared with reassessment performed one-month later.

At one month reassessment, educated students were, compared to controls, less convinced that PWS were unpredictable ("completely true" $8.7 \%$ (6/69) vs $26.0 \%$ (27/104), Mann-Whitney U test: $2328.0, p<.05)$, or easily recognizable ("not true" 63.5\% (47/64)vs 36.0\% (36/100), Mann-Whitney U test: 2656, $p<.05$ ) (Table 3). Furthermore, $64.9 \%$ (48/74) of the students in the experimental condition were firmly convinced that persons with this disorder could recover, compared to $35.9 \%$ (37/103) of controls (Mann-Whitney U test: 2686, $p<.05$; Table 2).

\section{DISCUSSION}

The results of this study confirm findings from previous research that students' attitudes toward PWS can be improved by training initiatives that include education and indirect contact with users (Haddock et al., 2014; Mann \& Himelein, 2008; Roe, Yanos \& Lysaker, 2006; Stubbs, 2014; Yamaguchi, Wu, Biswas, Yate, Aoki, Barley \& Thornicroft, 2013). Although these results do not allow us to affirm that psychology students became more eager to work with PWS as a consequence of this educational initiative, the data suggest that this intervention may engender in future psychologists a more balanced view of schizophrenia, denying neither the relevance of drug treatments, nor the importance of psychological therapies in the recovery process (Balter, 2014; Bellack, 2006; Davidson, Schmutte, Dinzeo \& Andres-Hyman, 2008; Majtabai et al., 1998).

One-month after the intervention, students more frequently reported stress and love disillusionment among the factors involved in the onset of schizophrenia, compared to baseline. Since the educational intervention did not specifically address the role of biological and psycho-social factors in the development and course of schizophrenia, it is likely that these findings are due to students' indirect exposure to PWS thought audio-taped testimonies (Corrigan \& Penn, 1999; Tibaldi \& Govers, 2012; Stubbs, 2014). In the testimonies, users recounted traumatic events they experienced before the onset and over the course of schizophrenia, and highlighted the factors which helped them to cope with negative events and the consequences of schizophrenia. Greater relevance attributed to psychological causal factors requiring effective psychological interventions may also partly explain the increased percentage of educated students who recommended psychologists for treatment at one-month 
reassessment. Listening to service users' testimonies may have also contributed to the increased usefulness attributed to both biological and psychological therapies by educated students at follow-up. For instance, one user outlined the beneficial effects of drugs to alleviate disturbing symptoms she experienced in critical periods but also the counterproductive effects of long-term drug therapies on her subsequent participation in psychotherapy (Tibaldi \& Govers, 2012). This view on antipsychotic drugs are in line with the increasing skepticism about the efficacy and even possible iatrogenic properties of antipsychotic when used long-term (Harrow \& Jobe, 2013; Weinmann, Read \& Aderhold, 2009; Whitaker, 2015; Wunderink, Nieboer, Wiersma, Sytema, \& Nienhuis, 2013). She also reported how useful she found "spoken therapy", particularly helpful to deal with past traumatic events and to feel supported in her recovery, and how "lucky" she felt for having "met a psychiatry with human face". These findings confirm the hypothesis that such an educational, contact-based initiative can facilitate students' acceptance of an integrated bio-psycho-social model of care in schizophrenia (Deacon \& McKay, 2015), and support the favorable changes found at immediate post intervention assessment in previous studies (Brown et al., 2010; Magliano et al., 2014; Mann \& Himelein, 2008).

The percentage of educated students who firmly believed that PWS can recover moved from $23.8 \%$ at baseline assessment to $64.9 \%$ at one-month reassessment. This encouraging result might be explained by students' exposure to: a) users' testimonies. In the testimonies, users acknowledged great relevance to the role of psychosocial factors - such as having friends, affective relationships, and a job - in their process of recovery, and outlined the usefulness of having received integrated bio-psycho-social treatments (Tibaldi \& Govers, 2012; Soundy, Stubbs, Roskell, Williams, Fox, \& Vancampfort, 2015; see Appendix 1 - Video-materials from the websites) within the framework of a reciprocal trust relationship with professionals; b) scientific evidence on the fact that more than $50 \%$ of PWS, if adequately supported, recover from this disorder (Levine, Lurie, Kohn, \& Levav, 2010; Tibaldi \& Govers, 2012).

At one-month after the intervention assessment, only $11.4 \%$ of educated students thought it was completely true that PWS are unpredictable. Moreover, the comparisons of educated and control groups highlight that educated students had a more optimistic views of schizophrenia and were less convinced that PWS are unpredictable, than controls. As far as students' perception of the dangerousness of PWS, change from baseline to one-month paired reassessment did not reach statistical significance, although a positive trend was observed ("not true": $7.1 \%$ vs. $25.3 \%$ ). This result suggests that providing students with epidemiological data demonstrating that the risk of aggressive behaviors is modest in those with schizophrenia - especially when PWS receive appropriate treatments and are not in acute psychotic episodes (Fazel, Langstrom, Hjern, Grann \& Lichtenstein, 
2009) - might be not sufficient to modify psychology students' deep-rooted beliefs about dangerousness. It is likely that a stronger education package also including direct contacts with PWS, is needed to challenge the toxic stereotype of people with mental disorders "as dangerous time bombs waiting to explode" (Ferriman, 2000), also fostered by the misuse of the word "schizophrenia" by media (Magliano, Read \& Marassi, 2011).

This is the first quasi-controlled trial carried out in Italy on the effects of an educational intervention addressing common prejudices toward PWS among psychology students. Among the strengths of the study are: the inclusion of all students in their $5^{\text {th }}$ year of Psychology studies- most of them will become clinical psychologists (Bosio \& Lozza, 2008); the quasi-randomized design, with re-assessment one-month after the intervention in educated students and at the same time in controls; and the low refusal rates. We considered as refusals those students that did not give back the anonymous questionnaire at one or both assessments $(9.6 \%)$. Positive features of the intervention are that it includes both didactic education and indirect contact with persons having, or having had, mental health problems - two strategies of proven efficacy in reducing stigma (Corrigan \& Penn, 1999; Yamaguchi et al., 2013), and that the intervention has been developed by a working group including students from medical and psychology schools who had received an ad-hoc training. These strengths support the generalizability of the findings of the study and might facilitate the replication of this educational initiative in other academic and non-academic contexts.

The study also has a number of limitations suggesting the need for caution in interpreting the results. In particular, the sample is predominantly female (nearly 90\%), a situation reflecting the high number of female students attending masters degrees in Psychology in Italy $(85.8 \%$, Consorzio Interuniversitario Alma Laurea, 2014), but meaning that the results are not generalizable to male students. Furthermore, the lack of blinding among both researchers and participants may have artificially enhanced, or exaggerated, the effects of the educational intervention. In future, this limitation can be managed by comparing the effects of two alternative interventions. Using two types of education intervention could also help overcome the credibility issues that arise when blinding is not possible. Moreover, the probability of contamination across the group cannot be excluded, since students in the same year of their psychology course were randomly assigned to educational or control groups. The alteration of the randomization is another limitation, since 18 students switched from education to control group. Since the questionnaire was anonymous, we were unable to identify the 18 students who moved from early education group to control group and exclude them from the analyses. These students may have been less interested in schizophrenia, increasing magnitude of differences between groups. Ethical implications should be considered, since the voluntary assessment of students' views was made in coincidence with laboratory works. To deal with 
these implications, the questionnaire was distributed to eligible participants and collected after 30 minutes by students who were not members of the research working group and in absence of the teacher. The one-month follow-up period does not allow us to verify whether the positive results persisted for a longer time; nor can we conclude that changes in beliefs about schizophrenia were predictive of changes in actual behaviors towards PWS. In order to assess the effect of the educational initiative at longer follow up, the provision of main Psychiatry course and related laboratory activities has been moved from the last to the first semester of the 5th year. Other limitations are the lack of information about students' previous knowledge of someone diagnosed with schizophrenia and the small sample size. It should be also considered the low Crombach alpha's value of the questionnaire. Given the poor internal consistency, we analyzed items separately in this study. Finally, social desiderability should be considered. However, the fact that the questionnaire was anonymous may have mitigated this bias.

On the basis of the encouraging results of this study and in line with literature findings on the usefulness of contact to improve university students attitudes towards people with mental disorders (for a systematic review see Yamaguchi et al., 2013), a video-testimony has been associated to the clinical presentation of each psychiatric disorder in the main Psychiatry course for $5^{\text {th }}$ year psychology students . Moreover, to reinforce the short-term improvement of psychology students' beliefs about the usefulness of psychological therapies for PWS, practical training in evidence based psychosocial approaches for schizophrenia and other severe mental problems (Mueser et al., 2013a; Mueser, Deavers, Penn, \& Cassisi, 2013b) has been included in the main Psychiatry course for the $5^{\text {th }}$ year psychology students. Results of these forthcoming initiatives - including the replication of the educational initiative to address psychology students' attitudes toward people with different psychiatric disorders - will be provided in future papers.

We are aware that it takes more than some educational activities to address deep-rooted beliefs and fears about interacting with PWS (Friedrich, Evans-Lacko, London, Rhydderch, Henderson \& Thornicroft, 2013). Deeper changes in the entire health professional training curricula are needed to address the toxic effects of stigma on future health professionals (Nordt, Rössler \& Lauber, 2006). However, we also believe that improving psychology students' attitudes toward PWS though educational initiatives can be a crucial first step towards increasing psychologists' willingness to support PWS by offering a broader range of treatments, provided by staff with more positive, less fearful, attitudes.

\section{ACKNOWLEDGMENTS}


The authors thank: a) Mrs. Alice Banfi, Ms. Lia Govers, Mrs. Madia Marangi, and Mrs. Giovanna O. for giving us their valuable testimonies; b) the 188 participating students for their active involvement in this study.

\section{CONFLICT OF INTEREST}

The authors declare that they have no conflicts of interests concerning this article.

\section{REFERENCES}

Aaltonen, J., Seikkula, J., \& Lehtinen, K. (2011). The Comprehensive Open-Dialogue Approach in Western Lapland: I. The incidence of non-affective psychosis and prodromal states. Psychosis, 3, 179-191. doi: $10.1080 / 17522439.2011 .601750$

Andreasen, N.C., Carpenter, W.T., Kane, J.M., Lasser, R.A., Marder, S.R., \& Weinberger, D.R. (2005). Remission in schizophrenia: proposed criteria and rationale for consensus. American Journal of Psychiatry, 162 (3), $441-449$.

Balter, M. (2014). Talking back to madness. Science, 343, 1190-1193. doi:10.1126/science.343.6176.1190

Bellack, A. S. (2006). Scientific and consumer models of recovery in schizophrenia: concordance, contrasts, and implications. Schizophrenia Bulletin, 32(3), 432-42. doi: 10.1093/schbul/sbj044.

Bosio, A.C., \& Lozza, E. Lo stato e le prospettive delle professioni psicologiche in Italia (The status and prospects of psychological professions in Italy) (2008). National Association of Psychologist. Retrived from www.psy.it/documents/Bosio_Lozza.pdf

Brown, S. A., Evans, Y., Espenschade, K., \& O'Connor, M. (2010). An examination of two brief stigma reduction strategies: filmed personal contact and hallucination simulations. Community Mental Health Journal, 46, 494499. doi: $10.1007 / \mathrm{s} 10597-010-9309-1$

Buck, B., Romeo, K. H., Olbert, C. M., \& Penn, D. L. (2014). Self-reported comfort treating severe mental illnesses among pre-doctoral graduate students in clinical psychology. Journal of Mental Health, 23, 297-302. doi: $10.3109 / 09638237.2014 .924048$

Consorzio Interuniversitario Alma Laurea (2014). Profilo dei laureati 2013 (Graduate students' profile). Retrived from: https://www.almalaurea.it/universita/profilo/profilo2013/volume

Corrigan, P. W., \& Penn, D. L. (1999). Lessons from social psychology on discrediting psychiatric stigma. American Psychology, 54, 765-776. 
Davidson, L., Schmutte, T., Dinzeo, T., \& Andres-Hyman, R. (2008). Remission and recovery in schizophrenia: practitioner and patient perspectives. Schizophrenia Bulletin, 34(1), 5-8. doi: 10.1093/schbul/sbm122.

Deacon, B. J. (2013). The biomedical model of mental disorder: a critical analysis of its validity, utility, and effects on psychotherapy research. Clinical Psychology Review, 33(7), 846-861. doi: 10.1016/j.cpr.2012.09.007

Deacon, B. J., \& McKay D. (2015). The Biomedical Model of Psychological Problems: A Call for Critical Dialogue. The behavior therapist, 38(7), 231-235. doi: 10.1016/j.cpr.2012.09.007.

Dixon, L. B., Dickerson, F., Bellack, A. S., Bennett, M., Dickinson, D., Goldberg, R. W., ... Schizophrenia Patient Outcomes Research Team (PORT) (2010). The 2009 schizophrenia PORT psychosocial treatment recommendations and summary statements. Schizophrenia Bulletin, 36, 48-70. doi: 10.1093/schbul/sbp115

Fazel, S., Langstrom, N., Hjern, A., Grann, M., \& Lichtenstein, P. (2009). Schizophrenia, substance abuse, and violent crime. The British journal of psychiatry. Supplement Royal College of Psychiatrists, 301, 2016-2023.

Ferriman, A. (2000). The stigma of schizophrenia. British Medical Journal, 320, 522.

Friedrich, B., Evans-Lacko, S., London, J., Rhydderch, D., Henderson, C., \& Thornicroft, G. (2013). Anti-stigma training for medical students: the Education Not Discrimination project. British Journal of Psychiatry Suppl, 55, s89-94. doi: 10.1192/bjp.bp.112.114017

Gaebel, W., Weinmann, S., Sartorius, N., Rutz, W., \& McIntyre, J. S. (2005). Schizophrenia practice guidelines: international survey and comparison. British Journal of Psychiatry, 187, 248-255. doi: 10.1192/bjp.187.3.248

Haddock, G., Eisner, E., Boone, C., Davies, G., Coogan, C., \& Barrowclough, C. (2014). An investigation of the implementation of NICE-recommended CBT interventions for people with schizophrenia. Journal of Mental Health, 23, 162-165. doi: 10.3109/09638237.2013.869571

Hansson, L., Vinding, H. R., Mackeprang, T., Sourander, A., Werdelin, G., Bengtsson-Tops, A.,... Middelboe, T. (2001). Comparison of key worker and patient assessment of needs in schizophrenic patients living in the community: a Nordic multicentre study. Acta Psychiatrica Scandinavica, 103(1), 45-51. doi: 10.1111/j.16000447.2001.00083.x

Harrow, M., \& Jobe, T. H. (2013). Does long-term treatment of schizophrenia with antipsychotic medications facilitate recovery? Schizophrenia Bulletin, 39(5), 962-5. doi: 10.1093/schbul/sbt034.

Howes, O. (2014) Cognitive therapy: at least an alternative to antipsychotics? Lancet, 383, 1364-1366. doi: 10.1016/S0140-6736(13)62569-6. 
Ince, P., Haddock, G., \& Tai, S. (2015). A systematic review of the implementation of recommended psychological interventions for schizophrenia: Rates, barriers, and improvement strategies. Psychology and Psychotherapy, 5-11. doi: 10.1111/papt.12084.

Kimhy, D., Tarrier, N., Essock, S., Malaspina, D., Cabannis, D., \& Beck, A. T. (2013). Cognitive Behavioral Therapy for Psychosis - Training Practices and Dissemination in the United States. Psychosis, 5(3). doi: $10.1080 / 17522439.2012 .704932$.

Kuller, A. M., Ott, B. D., Goisman, R. M., Wainwright, L. D., \& Rabin, R. J. (2010). Cognitive behavioral therapy and schizophrenia: a survey of clinical practices and views on efficacy in the United States and United Kingdom. Community Mental Health Journal, 46(1), 2-9. doi: 10.1007/s10597-009-9223-6.

Lehman, A. F., \& Steinwachs, D. M. (1998). Patterns of usual care for schizophrenia: initial results from the Schizophrenia Patient Outcomes Research Team (PORT) Client Survey. Schizophrenia Bulletin, 24(1), 1120. doi: 10.1093/oxfordjournals.schbul.a033303.

Levine, S. Z., Lurie, I., Kohn, R., \& Levav, I. (2010). Trajectories of the course of schizophrenia: From progressive deterioration to amelioration over three decades. Schizophrenia Research, 126, 184-191. doi: http://dx.doi.org/10.1016/j.schres.2010.10.026

Liberman, R. P., Kopelowicz, A., Ventura, J., \& Gutkind D. (2002). Operational criteria and factors related to recovery from schizophrenia. International Review of Psychiatry, 14, 256-272. doi: $10.1080 / 0954026021000016905$.

Liberman, R.P. (2008). Recovery from disability: manual of psychiatric rehabilitation. Washington, DC: American Psychiatric Pub.

Lincoln, T. M., Arens, E., Berger, C., \& Rief, W. (2008). Can antistigma campaigns be improved? A test of the impact of biogenetic vs psychosocial causal explanations on implicit and explicit attitudes to schizophrenia. Schizophrenia Bulletin, 34, 984-994. doi: 10.1093/schbul/sbm131

Lincoln, T.M., Wilhelm, K., \& Nestoriuc, Y. (2007). Effectiveness of psychoeducation for relapse, symptoms, knowledge, adherence and functioning in psychotic disorders: a meta-analysis. Schizophrenia Research, 96(13), 232-45. doi: 10.1016/j.schres.2007.07.022.

Magliano, L., Fiorillo, A., De Rosa, C., Malangone, C., \& Maj, M. (2004). Beliefs about schizophrenia in Italy: a comparative nationwide survey of the general public, mental health professionals, and patients' relatives. Canadian Journal of Psychiatry, 49(5), 322-330. 
Magliano, L., Read, J., \& Marassi, R. (2011). Metaphoric and non-metaphoric use of the term "schizophrenia" in Italian newspapers. Social Psychiatry and Psychiatric Epidemiology, 46, 1019-1025. doi: 10.1007/s00127010-0274-3.

Magliano, L., Read, J., Rinaldi, A., Costanzo, R., De Leo, R., Schioppa, G., Petrillo, M. (2015). The influence of causal explanations and diagnostic labeling on psychology students' beliefs about treatments, prognosis, dangerousness and unpredictability in schizophrenia. Community Mental health Journal, June 17, Epub ahead of print, doi: $10.1007 / \mathrm{s} 10597-015-9901-5$

Magliano, L., Read, J., Sagliocchi, A., Oliviero, N., D'Ambrosio, A., Campitiello, F., ...Patalano, M. (2014). "Social dangerousness and incurability in schizophrenia": results of an educational intervention for medical and psychology students. Psychiatry Research, 219, 457-463. doi: 10.1016/j.psychres.2014.06.002

Magliano, L., Read, J., Sagliocchi, A., Patalano, M., \& Oliviero, N. (2013). Effect of diagnostic labeling and causal explanations on medical students' views about treatments for psychosis and the need to share information with service users. Psychiatry Research, 210, 402-407. doi: 10.1016/j.psychres.2013.07.022

Magliano, L., Read, J., Sagliocchi, A., Patalano, M., D'Ambrosio, A., \& Oliviero, N. (2012). Differences in views of schizophrenia during medical education: a comparative study of 1 st versus 5 th-6th year Italian medical students. Social Psychiatry and Psychiatric Epidemiology, 48, 1647-1655. doi: 10.1007/s00127-012-0610-x

Mann, C. E., \& Himelein, M. J. (2008). Putting the person back into psychopathology: an intervention to reduce mental illness stigma in the classroom. Social Psychiatry and Psychiatric Epidemiology, 43, 545-551. doi: $10.1007 / \mathrm{s} 00127-008-0324-2$

McGorry, P., Alvarez-Jimenez, M., \& Killackey, E. (2013). Antipsychotic medication during the critical period following remission from first-episode psychosis: less is more. JAMA Psychiatry, 70(9), 898-900. doi: 10.1001/jamapsychiatry.2013.264.

Mojtabai, R., Fochtmann, L., Chang, S. W., Kotov, R., Craig, T. J., \& Bromet, E. (2009).Unmet need for mental health care in schizophrenia: an overview of literature and new data from a first-admission study. Schizophrenia Bulletin, 35(4), 679-95. doi: 10.1093/schbul/sbp045.

Mojtabai, R., Nicholson, R. A., \& Carpenter, B. N. (1998). Role of psychosocial treatments in management of schizophrenia: a meta-analytic review of controlled outcome studies. Schizophrenia Bulletin, 24(4), 569-87.

Morrison, A. (2013). Cognitive therapy for people experiencing psychosis. In J. Read, \& J. Dillon (Eds.), Models of Madness 2nd ed (pp. 319-335). London: Routledge. 
Morrison, A. P., Turkington, D., Pyle, M., Spencer, H., Brabban, A., Dunn, G., ... Hutton, P. (2014). Cognitive therapy for people with schizophrenia spectrum disorders not taking antipsychotic drugs: a single-blind randomised controlled trial. The Lancet, 383, 1395-1403. doi: 10.1016/S0140-6736(13)62246-1.

Mueser, K. T., Deavers, F., Penn, D. L., \& Cassisi, J. E. (2013b). Psychosocial treatments for schizophrenia. Annual Review of Clinical Psychology, 9, 465-497. doi: 10.1146/annurev-clinpsy-050212-185620

Mueser, K. T., Silverstein, S. M., \& Farkas, M. D. (2013a). Should the training of clinical psychologists require competence in the treatment and rehabilitation of individuals with a serious mental illness? Psychiatric Rehabilitation Journal, 36(1), 54-9. doi: 10.1037/h0094750.

NICE (2014). Schizophrenia. National Institute of Clinical Excellence. CG178. Retrived from http://www.nice.org.uk/guidance/CG178

Nordt, C., Rössler, W., \& Lauber, C. (2006). Attitudes of mental health professionals toward people with schizophrenia and major depression. Schizophrenia Bulletin, 32, 709-714.

Pfammatter, M, Junghan, U. M., \& Brenner, H. D. (2006). Efficacy of psychological therapy in schizophrenia: conclusions from meta-analyses. Schizophrenia Bulletin, 32(1), 64-80.

Pharoah, F., Mari, J., Rathbone, J., \& Wong, W. (2010). Family intervention for schizophrenia. The Cochrane Database of Systematic Reviews, 12, CD000088. doi: 10.1002/14651858.CD000088.pub2

Prytys, M., Garety, P. A., Jolley, S., Onwumere, J., \& Craig, T. (2011). Implementing the NICE guideline for schizophrenia recommendations for psychological therapies: a qualitative analysis of the attitudes of CMHT staff. Clinical Psychology \& Psychotherapy, 18(1), 48-59. doi: 10.1002/cpp.691.

Read, J., \& Harré, N. (2001). The role of biological and genetic causal beliefs in the stigmatisation of the "mental patients". Journal of Mental Health, 10, 223-235. doi: 10.1080/09638230020023778

Read, J., \& Law, A. (1999). The relationship of causal beliefs and contact with users of mental health services to attitudes to the 'mentally ill'. International Journal of Social Psychiatry, 45, 216-229.

Read, J., Magliano, L., \& Beavan, V. (2013). Public beliefs about the causes of "schizophrenia": bad things happen and can drive you crazy. In J. Read \& J. Dillon (Eds.), Models of Madness, 2nd ed. (pp. 143-156). London: Routledge

Reddy F., Spaulding W..D., Jansen M.A., Menditto A.A., Pickett S. (2010). Psychologists' rolee and opportunities in rehabilitation and recovery from serious mental illness: a survey of the Council of University Directors of Clinical Psychology (CUDCP), clinical psychology training and doctoral education. Training and Education in Professional Psychology, 4, 254-263. 
Revell, E. R., Neill, J. C., Harte, M., Z., \& Drake, R. J. (2015). A systematic review and meta-analysis of cognitive remediation in early schizophrenia. Schizophrenia Research, 168(1-2), 213-22. doi: 10.1016/j.schres.2015.08.017.

Roe, D., Yanos, P. T., \& Lysaker, P. H. (2006). Overcoming barriers to increase the contribution of clinical psychologists to work with persons with severe mental illness. Clinical Psychology, 13, 376-383. doi: $10.1111 / j .1468-2850.2006 .00051 . x$

Sarin, F., Wallin, L., \& Widerlöv, B. (2011). Cognitive behavior therapy for schizophrenia: a meta-analytical review of randomized controlled trials. Nordic Journal of Psychiatry, 65, 162-174. doi: $10.3109 / 08039488.2011 .577188$

Seikkula, J., Aaltonen, J., Alakare, B., Haarakangas, K., Keränen, J., \& Lehtinen, K. (2006). Five-year experience of first-episode nonaffective psychosis in open-dialogue approach: Treatment principles, follow-up outcomes, and two case studies. Psychotherapy Research, 16(2), 214-228. doi:10.1080/10503300500268490.

Seikkula, J., Alakare, B. \& Aaltonen, J. (2011). The Comprehensive Open-Dialogue Approach in Western Lapland: II. Long-term stability of acute psychosis outcomes in advanced community care. Psychosis, 3, 192204. doi: $10.1080 / 17522439.2011 .595819$

Semisa, D., Lasalvia, A., Miceli, M., Dall'Agnola, R. B., Pucci, C., Bissoli, S.,... SIEP-DIRECT working group (2008). The acceptability of the NICE recommendations for schizophrenia in the Italian Departments of Mental Health. The SIEP-DIRECT'S Project on the discrepancy between routine practice and evidence. Epidemiologia e Psichiatria Sociale, 17, 291-304.

Serafini, G., Pompili, M., Haghighat, R., Pucci, D., Pastina, M., Lester... Girardi, P. (2011). Stigmatization of schizophrenia as perceived by nurses, medical doctors, medical students and patients. Journal of Psychiatric and Mental Health Nursing, 18(7), 576-85. doi: 10.1111/j.1365-2850.2011.01706.x.

Servais, L. M., \& Saunders, S. M. (2007). Clinical Psychologists' Perceptions of Persons With Mental Illness. Professional Psychology: Research and Practice, 38, 214-219. doi: 10.1037/0735-7028.38.2.214

Soundy, A., Stubbs, B., Roskell, C., Williams, S. E., Fox, A., \& Vancampfort, D. (2015). Identifying the facilitators and processes which influence recovery in individuals with schizophrenia: a systematic review and thematic synthesis. Journal of Mental Health, 1-8. doi: 10.3109/09638237.2014.998811.

Stubbs, A. (2014). Reducing mental illness stigma in health care students and professionals: a review of the literature. Australian Psychiatry, 22, 579-584. doi: 10.1177/1039856214556324. 
Substance Abuse and Mental Health Services Administration (2005). National Consensus Conference on Mental Health Recovery and Systems Transformation. Department of Health and Human Services, Rockville, Maryland.

Tibaldi, G., \& Govers, L. (2012). Evidence-based hope for recovery from "schizophrenia": A common objective for all stakeholders in the mental health field. Psychosis, 4, 105-114. doi: 10.1080/17522439.2011.584349.

Varese, F., Smeets, F., Drukker, M., Lieverse, R., Lataster, T., Viechtbauer, W., ... Bentall, R. P. (2012). Childhood adversities increase the risk of psychosis: a meta-analysis of patient-control, prospective- and crosssectional cohort studies. Schizophrenia Bulletin, 38, 661-671. doi: 10.1093/schbul/sbs050.

Weinmann, S., Read, J., \& Aderhold, V. (2009). The influence of antipsychotics on mortality in schizophrenia: A systematic review. Schizophrenia Research, 113, 1-11. doi: 10.1016/j.schres.2009.05.018.

Whitaker, R. (2015). Anatomy of an Epidemic: The history and science of a failed paradigm of care. The Behavior Therapist, 38, 192-198.

Wunderink, L., Nieboer, R. M., Wiersma, D., Sytema, S., \& Nienhuis, F. J. (2013) .Recovery in remitted firstepisode psychosis at 7 years of follow-up of an early dose reduction/discontinuation or maintenance treatment strategy: long-term follow-up of a 2-year randomized clinical trial. JAMA Psychiatry, 70(9), 913-20. doi: 10.1001/jamapsychiatry.2013.19.

Wykes, T., Huddy, V., Cellard, C., McGurk, S. R., \& Czobor, P. (2011). A meta-analysis of cognitive remediation for schizophrenia: methodology and effect sizes. American Journal of Psychiatry, 168(5), 472-85. doi: 10.1176/appi.ajp.2010.10060855.

Yamaguchi, S., Wu, S. I., Biswas, M., Yate, M., Aoki, Y., Barley, E. A., \& Thornicroft, G. (2013). Effects of short-term interventions to reduce mental health-related stigma in university or college students: a systematic review. Journal of Nervous and Mental Diseases, 201, 490-503. doi: 10.1097/NMD.0b013e31829480df 


\section{APPENDIX 1- Materials used in the educational intervention}

$\underline{\text { Video materials from websites }}$

Bring Change 2 Mind, 2009. Change a mind about mental illness. http://www.bringchange2mind.org/videos/entry/change-a-mind-about-mental-illness

ILGA Portugal-PT, 2008. Right of nonchalance - spot against omophobia. http://www.youtube.com/watch?v=5Op7INlzM5M

Time to change, 2010. 'Schizo The Movie' - a mental health anti-stigma trailer http://news.bbc.co.uk/2/hi/uk_news/8192603.stm

http://www.douglas.qc.ca/videos/194

http://www.douglas.qc.ca/videos/200

http://www.douglas.qc.ca/videos/197

Papers, books, and websites

Bellack A.S., 2006 Scientific and consumer models of recovery in schizophrenia: concordance, contrasts, and implications. Schizophrenia Bulletin 32, 432-442.

Tosi Cambini S., 2008. La zingara rapitrice. Racconti, denunce, sentenze (1986-2007), Roma, Cisu.

Corrigan P. W., 2004. Beat the stigma and discrimination! - four lessons for mental health advocates. Center for Psychiatric Rehabilitation at Evanston Northwestern Healthcare and The Chicago Consortium for Stigma Research. http://www.stigmaandempowerment.org/resources

Fazel S., Långström N., Hjern A., Grann M., Lichtenstein P., 2009. Schizophrenia, substance abuse, and violent crime. JAMA 301, 2016-2023.

Harrison G., Hopper K., Craig T., Laska E., Siegel C., Wanderling J., Dube K.C., Ganev K., Giel R., an der Heiden W., Holmberg S.K., Janca A., Lee P.W., León C.A., Malhotra S., Marsella A.J., Nakane Y., Sartorius N., Shen Y., Skoda C., Thara R., Tsirkin S.J., Varma V.K., Walsh D., Wiersma D., 2001. Recovery from psychotic illness: a 15- and 25-year international follow-up study. British Journal of Psychiatry 178, 506-517.

Harrow M., Grossman L.S., Jobe T.H., Herbener E.S., 2005. Do patients with schizophrenia ever show periods of recovery? A 15-year multi-follow-up study. Schizophrenia Bulletin 31, 723-734.

Jablenski A., Sartorius N., 2008. What did the WHO studies really find? Schizophrenia Bulletin 34, 253-255. 
Large M., Smith G., Nielssen O., 2009. The relationship between the rate of homicide by those with schizophrenia and the overall homicide rate: a systematic review and meta-analysis. Schizophrenia Research 112, 123-129.

Large M., Smith G., Swinson N., Shaw J., Nielssen O, 2008. Homicide due to mental disorder in England and Wales over 50 years. British Journal of Psychiatry 193, 130-133.

Liberman R., Kopelowitz A., 2005. Recovery from schizophrenia: a concept in search of research. Psychiatric Services $56,735-742$.

Lieberman J.A., Drake R.E., Sederer L.I., Belger A., Keefe R., Perkins D.,, Stroup S., 2008. Science and recovery in Schizophrenia. Psychiatric Services 59, 87-496.

The National Consortium on Stigma and Empowerment http://www.stigmaandempowerment.org/

Tibaldi G., Govers L., 2009. Evidence-based hope. La proposta di una prospettiva comune. Psichiatria di Comunità 3, 117-128.

Warner R., 2005. Recovery from schizophrenia: psychiatry and political economy. Routledge, London.

\section{$\underline{\text { Testimonies }}$}

Banfi A., 2009. "La mia pazza... gravipanza!". Forum Salute Mentale. http://www.newsforumsalutementale.it/wp-content/plugins/as-pdf/generate.php?post=2195

Govers L., 2009. "Lo psichiatra mi inseguiva a piedi per le strade di Torino". Parlare con le voci. http://www.parlaconlevoci.it/storie/pdf/Lia_Govers_Lo_psichiatra_mi_inseguiva_a_piedi.pdf Marangi M., 2011. Lecture at the Second Edition of the Trieste Meeting "Impazzire si può". Forum Salute Mentale. http://www.news-forumsalutementale.it/impazzire-si-puo-lintervento-di-madia-marangi/ 


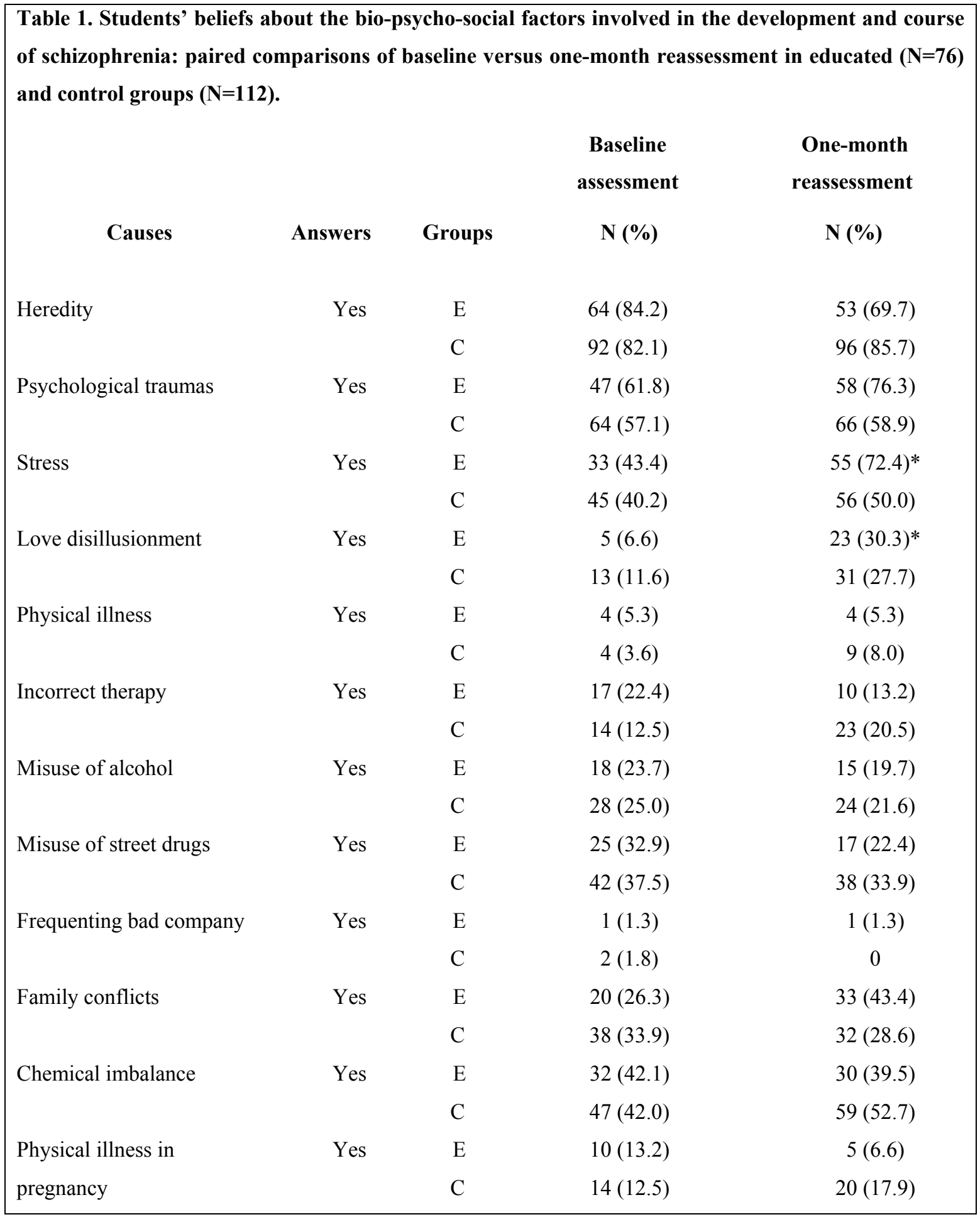

$\mathrm{E}=$ Educated group; $\mathrm{C}=$ Control group; $* \mathrm{Mc}$ Nemar test for paired data, $p<.05$ with Bonferroni correction 


\begin{tabular}{|c|c|c|c|c|}
\hline \multirow[t]{2}{*}{ Items } & Answers & Groups & Baseline assessment & $\begin{array}{l}\text { One-month } \\
\text { reassessment }\end{array}$ \\
\hline & & & N (\%) & $\mathbf{N}(\%)$ \\
\hline \multirow[t]{6}{*}{ PWS can recover } & Not true & E & $2(3.2)$ & $2(2.7)$ \\
\hline & Partially true & & $46(73.0)$ & $24(32.4)$ \\
\hline & Totally true & & $15(23.8)$ & $48(64.9)^{*}$ \\
\hline & Not true & $\mathrm{C}$ & $7(7.4)$ & $6(5.8)$ \\
\hline & Partially true & & $66(70.2)$ & $60(58.3)$ \\
\hline & Totally true & & $21(22.3)$ & $37(35.9)$ \\
\hline \multirow{6}{*}{$\begin{array}{l}\text { Drug treatments are } \\
\text { useful in schizophrenia }\end{array}$} & Not true & $\mathrm{E}$ & $5(6.7)$ & 0 \\
\hline & Partially true & & $45(60.0)$ & $35(46.1)$ \\
\hline & Totally true & & $25(33.3)$ & $41(53.9)^{*}$ \\
\hline & Not true & $\mathrm{C}$ & $3(2.7)$ & $1(0.9)$ \\
\hline & Partially true & & $65(59.1)$ & $62(55.4)$ \\
\hline & Totally true & & $42(38.2)$ & $49(43.8)$ \\
\hline \multirow{6}{*}{$\begin{array}{l}\text { Psychological treatments } \\
\text { are useful in } \\
\text { schizophrenia }\end{array}$} & Not true & E & 0 & 0 \\
\hline & Partially true & & $31(40.8)$ & $11(14.7)$ \\
\hline & Totally true & & $45(59.2)$ & $64(85.3)^{*}$ \\
\hline & Not true & $\mathrm{C}$ & $1(0.9)$ & $1(0.9)$ \\
\hline & Partially true & & $42(38.5)$ & $35(31.3)$ \\
\hline & Totally true & & $66(60.6)$ & $76(67.9)$ \\
\hline
\end{tabular}

$\mathrm{E}=$ Educated group; $\mathrm{C}=$ Control group; * Wilcoxon signed-rank test for paired data, $p<.05$ with Bonferroni correction 


\begin{tabular}{|c|c|c|c|c|}
\hline \multirow[t]{2}{*}{ Items } & \multirow[t]{2}{*}{ Answers } & \multirow[t]{2}{*}{ Groups } & $\begin{array}{c}\text { Baseline } \\
\text { assessment }\end{array}$ & One-month reassessment \\
\hline & & & $\mathbf{N}(\%)$ & $\mathbf{N}(\%)$ \\
\hline \multirow[t]{6}{*}{ PWS are dangerous } & Not true & E & $5(7.1)$ & $19(25.3)$ \\
\hline & Partially true & & $60(85.7)$ & $54(72.0)$ \\
\hline & Totally true & & $5(7.1)$ & $2(2.7)$ \\
\hline & Not true & $\mathrm{C}$ & $3(2.9)$ & $9(8.4)$ \\
\hline & Partially true & & $87(84.5)$ & $91(85.0)$ \\
\hline & Totally true & & $13(12.6)$ & $7(6.5)$ \\
\hline \multirow[t]{6}{*}{ PWS are unpredictable } & Not true & $\mathrm{E}$ & $5(7.1)$ & $24(34.8)$ \\
\hline & Partially true & & $40(57.1)$ & $39(56.5)$ \\
\hline & Totally true & & $25(37.5)$ & $6(8.7)^{*}$ \\
\hline & Not true & $\mathrm{C}$ & $5(4.6)$ & $9(8.7)$ \\
\hline & Partially true & & $57(52.8)$ & $68(65.4)$ \\
\hline & Totally true & & $46(42.6)$ & $27(26.0)$ \\
\hline \multirow[t]{6}{*}{ PWS are recognizable } & Not true & $\mathrm{E}$ & $28(38.4)$ & $47(63.5)$ \\
\hline & Partially true & & $40(54.8)$ & $24(32.4)$ \\
\hline & Totally true & & $5(6.8)$ & $3(4.1)^{*}$ \\
\hline & Not true & $\mathrm{C}$ & $37(35.2)$ & $36(36.0)$ \\
\hline & Partially true & & $55(52.4)$ & $55(55.0)$ \\
\hline & Totally true & & $13(12.4)$ & $9(9.0)$ \\
\hline
\end{tabular}

$\mathrm{E}=$ Educated group; $\mathrm{C}=$ Control group; *Wilcoxon signed-rank test for paired data, $p<.05$ with Bonferroni correction 
Figure 1. Participants Flow Diagram

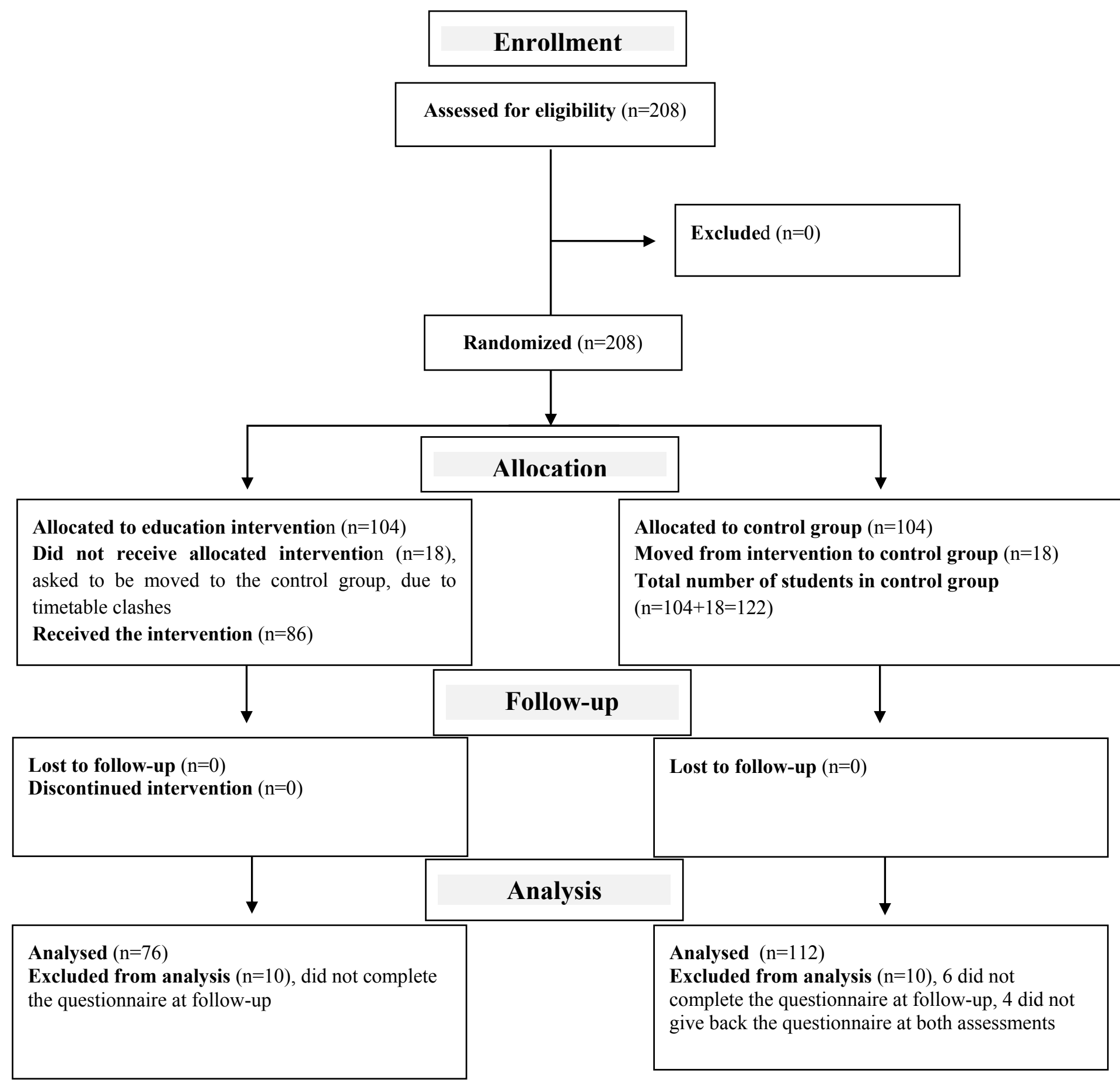

